\title{
Abstracts of Scientific Papers and Posters Presented at the Fourteenth Annual Meeting of the Dysphagia Research Society, Scottsdale, Arizona, USA, March 23-26, 2006
}

In the html abstract portion of the online publication of "Fourteenth Annual Dysphagia Research Society Meeting, March 23-26, 2006" (DOI: 10.1007/s00455-006-9044-5) the title and author information were erroneously stated. The information should have appeared as above. Springer regrets the errors. 